\title{
Cardiac Ion Channel Gene Mutations in Sudden Infant Death Syndrome
}

\author{
TESSHU OTAGIRI, KAZUKI KIJIMA, MOTOKI OSAWA, KUNIAKI ISHII, NAOMASA MAKITA, RYOJI MATOBA, \\ KAZUO UMETSU, AND KIYOSHI HAYASAKA
}

\begin{abstract}
Department of Pediatrics [T.O., K.K., K.H.], Department of Pharmacology [K.I.], and Department of Forensic Medicine [K.U.], Yamagata University School of Medicine, Yamagata 990-9585, Japan; Department of Forensic Medicine [M.O.], Tokai University School of Medicine, Sagamihara 259-1193, Japan; Department of Cardiovascular Medicine [N.M.], Hokkaido University Graduate School of Medicine, Sapporo 060-8638, Japan; Department of Legal Medicine [R.M.], Osaka University Graduate School of Medicine, Osaka 565-0871, Japan
\end{abstract}

\begin{abstract}
Sudden infant death syndrome (SIDS) is multifactorial and may result from the interaction of a number of environmental, genetic, and developmental factors. We studied three major genes causing long QT syndrome in 42 Japanese SIDS victims and found five mutations, KCNQ1-K598R, KCNH2-T895M, SCN5A-F532C, SCN5A-G1084S, and SCN5A-F1705S, in four cases; one case had both $K C N H 2-T 895 \mathrm{M}$ and $S C N 5 A-G 1084 \mathrm{~S}$. All mutations were novel except for SCN5A-F532C, which was previously detected in an arrhythmic patient. Heterologous expression study revealed significant changes in channel properties of KCNH2-T895M, SCN5AG1084S, and SCN5A-F1705S, but did not in KCNQ1-K598R and SCN5A-F532C. Our data suggests that nearly $10 \%$ of SIDS victims in Japan have mutations of the cardiac ion channel genes similar to in other countries. (Pediatr Res 64: 482-487, 2008)
\end{abstract}

$\mathrm{S}^{\mathrm{u}}$ udden infant death syndrome (SIDS) is defined as the sudden unexpected death of an infant $<1 \mathrm{y}$ of age, with onset of the fatal episode apparently occurring during sleep, which remains unexplained after thorough investigation (1). Its incidence differs among racial and ethnic groups, being estimated at 0.3-1.0/1000 live births in the United States $(2,3)$ and $0.3-0.5 / 1000$ in Japan.

SIDS is multifactorial and may result from the interaction of a number of environmental, genetic, and developmental factors. The well-known environmental risk factors are prone sleeping, smoking during pregnancy, and nonbreast feeding. Concerning the genetic factors, several genes have been investigated in cases of SIDS (4). Mutations or polymorphic changes associated with SIDS have been reported in the following: complements $(C 4 A, C 4 B)(5,6)$, IL-10 (7), mitochondrial DNA (MTTL1, MTND1), serotonin transporter (5HTT) $(8,9)$, a gene associated with sex differentiation (TSPYL) (10), and cardiac ion channels (KCNQ1, KCNH2, SCN5A). We have previously investigated the relationship between SIDS and congenital central hypoventilation syndrome (CCHS); however, we failed to find any mutations other than three single

Received March 18, 2008; accepted June 18, 2008.

Correspondence: Tesshu Otagiri, M.D., Department of Pediatrics, Yamagata University School of Medicine, 2-2-2 Iida-nishi, Yamagata 990-9585, Japan; e-mail: otagiri@med.id.yamagata-u.ac.jp

Supported in part by grants from the Ministry of Education, Culture, Sports, and Science, Japan. nucleotide polymorphisms (SNPs) of $P H O X 2 B$, a gene responsible for CCHS, in 48 Japanese SIDS victims $(11,12)$.

Recently, cardiac abnormalities causing life-threatening arrhythmias have attracted attention in association with SIDS. Long QT syndrome (LQTS) is a genetic disease characterized by a prolonged QT interval on the electrocardiogram (ECG) and a major cause of malignant ventricular tachyarrhythmias $(13,14)$. Association of SIDS and LQTS has been recognized since the first report in 1976 (15), and recent studies have demonstrated genetic link between SIDS and LQTS, suggesting that $2-10 \%$ of SIDS cases are attributable to the mutations in LQTS genes, especially in SCN5A (16-24).

Considering the variation in the incidence of SIDS and cardiac channelopathy among racial and ethnic groups, it is possible that the prevalence of the mutations in LQTS genes will differ among racial and ethnic groups. Therefore, we performed a molecular analysis of the three major genes causative of LQTS in Japanese SIDS victims.

\section{METHODS}

SIDS cohort. Between 1995 and 2004, a total of 50 cases of SIDS were investigated at four institutes of forensic medicine in Japan. The death certificate was assigned a diagnosis of SIDS if the autopsy, toxicology, and review of the circumstances of death were all negative. Eight cases were eliminated from the study because of DNA degeneration in their specimens. The main characteristics of the 42 cases were: 23 male and 19 female; median (range) age at time of death: 4 mo ( $5 \mathrm{~d}$ to $11 \mathrm{mo})$. Written informed consent was not always required for the study and the molecular analyses were conducted with the investigators blinded to the identities of the infant victims. The Ethics Committee of the Yamagata University School of Medicine approved this study.

Genetic analyses. Genomic DNA was extracted from frozen tissues or fresh blood from SIDS victims and control subjects. All exons, including the exon-intron boundaries of $K C N Q 1, K C H H 2$, and $S C N 5 A$, were amplified using the polymerase chain reaction and amplicons were screened for mutations by denaturing HPLC (Transgenomic Inc., Omaha, NE). Fragments showing a heteroduplex were sequenced. An analysis of 150 control subjects verified putative disease-causing mutations.

Molecular biology. cDNAs of KCNQ1 and SCN5A and a cDNA of $K C N H 2$ were introduced into the expression vectors pcDNA3.1 and pcDNA3 (Invitrogen, Carlsbad, CA), respectively. A cDNA of $K C N E 1(\min K) \beta$-subunit was subcloned in pCR-Script (Stratagene, La Jolla, CA). Mutations of each gene were introduced using the QuikChange site-directed mutagenesis kit (Stratagene, La Jolla, CA). The presence of the desired mutations and absence of unwanted changes in the clones were verified by DNA sequencing.

Abbreviation: LQTS, long QT syndrome 
Gene-expression studies of KCNQ1 and $\mathrm{KCNH}$. The plasmids containing mutant and wild-type (WT) $K C N Q 1, K C N H 2$, and $K C N E 1 \mathrm{cDNA}$ were linearized with appropriate restriction enzymes and capped cRNAs were synthesized in vitro using either T3 RNA polymerase (KCNE1) or T7 RNA polymerase $(K C N Q 1$ and $K C N H 2)$ with a mMESSAGE mMACHINE kit (Ambion, Austin, TX).

The oocytes (stage V and VI) of Xenopus laevis were prepared according to ordinary methods (25). Each of the oocytes was injected with either $9.2 \mathrm{ng}$ of WT or mutant $K C N Q 1$ cRNA with $1.7 \mathrm{ng}$ of $K C N E 1 \mathrm{cRNA}$, or $9.2 \mathrm{ng}$ of WT or mutant $K C N H 2$ cRNA and incubated at $18^{\circ} \mathrm{C}$ for 2 to $4 \mathrm{~d}$ before electrophysiological measurements. Whole-cell currents were recorded from oocytes by the two-microelectrode voltage-clamp technique and data acquisition was performed as described previously (26).

Gene-expression studies of SCN5A. The human kidney cell line tsA-201 was transiently transfected with the plasmids encoding WT or mutant SCN5A in combination with a bicistronic plasmid (pCD8-IRES-h $\beta 1$ ) encoding CD8 and the human $\beta 1$ subunit (h $\beta 1$ ) to visually identify cells expressing heterologous $\mathrm{h} \beta 1$ with Dynabeads M-450 CD8 (Dynal, Oslo, Norway) using the SuperFect Transfection Reagent (Qiagen Inc., Valencia, CA).

Electrophysiological measurements were obtained 24 to $72 \mathrm{~h}$ after transfection. Na currents were recorded and analyzed using the whole-cell patch clamp technique as described previously (27).

Data analysis. Data analysis was performed using the Clampfit program (pCLAMP 9.2, Axon Instruments, Union City, CA) and SigmaPlot (SPSS Inc., Chicago, IL). Curve fitting was accomplished using a nonlinear least squares minimization method. The time course of inactivation in $I_{\mathrm{Na}}$ and of deactivation in $I_{\mathrm{Kr}}$ were fit with the following biexponential function:

$$
I / I_{\max }=\mathrm{A}_{0}+\mathrm{A}_{\mathrm{f}} \times \exp \left(-\mathrm{t} / \tau_{\mathrm{f}}\right)+\mathrm{A}_{\mathrm{s}} \times \exp \left(-\mathrm{t} / \tau_{\mathrm{s}}\right)
$$

where $\mathrm{A}_{0}$ refers to a constant value, $\mathrm{A}_{\mathrm{f}}$ and $\mathrm{A}_{\mathrm{s}}$ to the fractions of fast and slow inactivating components, respectively, and $\tau_{\mathrm{f}}$ and $\tau_{\mathrm{s}}$ to the time constants of fast and slow inactivating components, respectively. Steady state availability in $I_{\mathrm{Na}}$, and the voltage dependence of channel activation were fit with the Boltzmann equation

$$
I / I_{\max }=\left\{1+\exp \left[\left(V-V_{0.5}\right) / \kappa\right]\right\}^{-1}
$$

to determine the membrane potential for half-maximal inactivation or activation $\left(V_{0.5}\right)$ and the slope factor $\kappa$. Voltage dependence of activation in $I_{\mathrm{Na}}$ was estimated by measuring peak sodium current during a variable test potential from a holding potential of $-120 \mathrm{mV}$. Recovery from inactivation in $I_{\mathrm{Na}}$ was analyzed by fitting data with the following biexponential function:

$$
I / I_{\max }=\mathrm{A}_{\mathrm{f}} \times\left[1-\exp \left(-\mathrm{t} / \tau_{\mathrm{f}}\right)\right]+\mathrm{A}_{\mathrm{s}} \times\left[1-\exp \left(-\mathrm{t} / \tau_{\mathrm{s}}\right)\right]
$$

Results are presented as the mean \pm SE. Statistical comparisons were made between WT and mutants using the unpaired $t$ test. Statistical significance was assumed for $p<0.05$ (two-sided)

\section{RESULTS}

Postmortem genetic analyses of the SIDS cohort. Genetic analysis revealed five mutations, KCNQ1-K598R, KCNH2T895M, SCN5A-F532C, SCN5A-G1084S, and SCN5AF1705S, in four cases; one case had both $K C N H 2-T 895 \mathrm{M}$ and SCN5A-G1084S (Table 1).

Case-62 had a missense mutation, K598R (c.1793A > G), within the C-terminal region of $K C N Q 1$. K598R is expected to replace an evolutionally conserved residue that is shared by the KCNQ potassium channel family.

Case-9 had one missense mutation, T895M (c.2684C > T), within the C-terminal region of $\mathrm{KCNH} 2$ and another, G1084S (c.3250G > A), in the IIS6-IIIS1 region of SCN5A. T895 of $K C N H 2$ is conserved among various species, but G1084 of $S C N 5 A$ is conserved only in the rat and mouse.

Case-63 had a missense mutation, F532C (c.1595T > G), at IS6-IIS1 of SCN5A. F532C was previously detected in an adult patient with arrhythmia (28).
Table 1. Compendium of identified mutations

\begin{tabular}{clcll}
\hline Case no. & Gene & Exon & Variant & \multicolumn{1}{c}{ Location } \\
\hline 62 & KCNQ1 & 15 & K598R* & C-terminus \\
$9^{\dagger}$ & KCNH2 & 11 & T895M* & C-terminus \\
& SCN5A & 18 & G1084S* & II S6-III S1 \\
40 & SCN5A & 28 & F1705S* & IV S5-IV S6 \\
63 & SCN5A & 12 & F532C & I S6-II S1
\end{tabular}

* Novel mutations.

$\dagger$ Compound heterozygosity with KCNH2-T895M and SCN5A-G1084S.

Case-40 had a missense mutation, F1705S (c.5114T $>$ C), at IVS5-IVS6 of SCN5A. F1705 is located in the pore region and is highly conserved among various species.

Four mutations except SCN5A-F532C were novel and were not found in 150 healthy Japanese controls. Several registered or nonregistered SNPs were also detected in this cohort.

Electrophysiological characterization of mutant channels. WT or K598R KCNQ1 channels expressed in oocytes elicited slowly activating and deactivating $I_{\mathrm{Ks}}$ currents $(29,30)$. There were no significant differences in the current-voltage relationship, voltage dependence of activation, or activation and deactivation kinetics (data not shown). The K598R mutation did not noticeably alter the gating of $K C N Q 1$ channels expressed in oocytes.

Figure $1 A$ shows typical WT and T895M KCNH2 currents. The current-voltage relationships at the end of 2 s depolarizing voltage steps showed a strong inward rectification at potentials positive to $-10 \mathrm{mV}$ in both WT and mutant channels because of fast C-type inactivation (31-33). T895M showed significantly reduced steady-state currents as compared with WT at test potentials between -50 and $+20 \mathrm{mV}\left(p<0.001\right.$ at $V_{\mathrm{m}}$ between -50 and $0 \mathrm{mV}, p<0.05$ at $V_{\mathrm{m}}$ of +10 and +20 $\mathrm{mV})($ Fig. $1 B)$. There was no significant difference in peak-tail current between WT and T895M (Fig. 1B). The voltage dependence of activation in T895M displayed a $3 \mathrm{mV}$ shift in the positive direction compared with that in WT (Fig. 1C). Although both data, $V_{0.5}$ and slope factor, showed statistically significant differences between WT and T895M $\left\{\mathrm{WT}: V_{0.5}=\right.$ $-22.6 \pm 0.4 \mathrm{mV}, \kappa=9.3 \pm 0.3$; $\mathrm{T} 895 \mathrm{M}: V_{0.5}=-19.4 \pm 0.4$ $\mathrm{mV}(p<0.001), \kappa=7.6 \pm 0.1(p<0.001)\}$, the effect on clinical condition may be equivocal because of these small differences. The deactivation time course in T895M was significantly slower than that in WT for both fast and slow components between a $V_{\mathrm{m}}$ of -60 and $-40 \mathrm{mV}(p<0.001)$ (Fig. 2).

SCN5A-WT, SCN5A-F532C, SCN5A-G1084S, and SCN5AF1705S were transiently expressed in the human kidney cell line tsA-201. Heterologously expressed three mutant Na channels showed robust Na currents (Fig. 3). The macroscopic current decay of WT and mutants was comparable, and a persistent $\mathrm{Na}^{+}$current, characteristic for the most LQT3 mutant Na channels, was not evident in those channels. The SCN5A-F532C channel did not show any significant difference in gating properties in the expression experiments (data not shown). The voltage dependence of steady-state inactivation of G1084S showed a small but significant hyperpolarizing shift by $-5.5 \mathrm{mV}$ \{WT: $V_{0.5}=-88.3 \pm 0.8 \mathrm{mV}, \kappa=7.5 \pm$ 0.1 ; G1084S: $V_{0.5}=-93.8 \pm 1.3 \mathrm{mV}(p<0.05), \kappa=7.0 \pm$ 
A
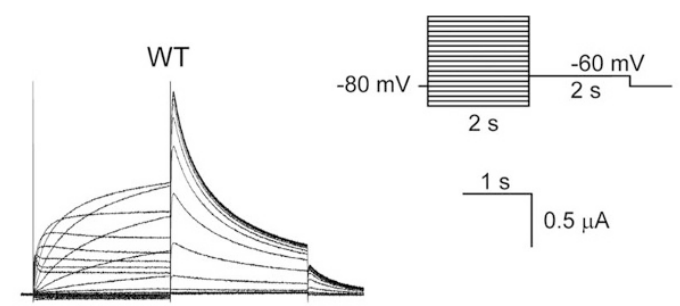

$\stackrel{1 \mathrm{~s}}{ } 0.5 \mu \mathrm{A}$
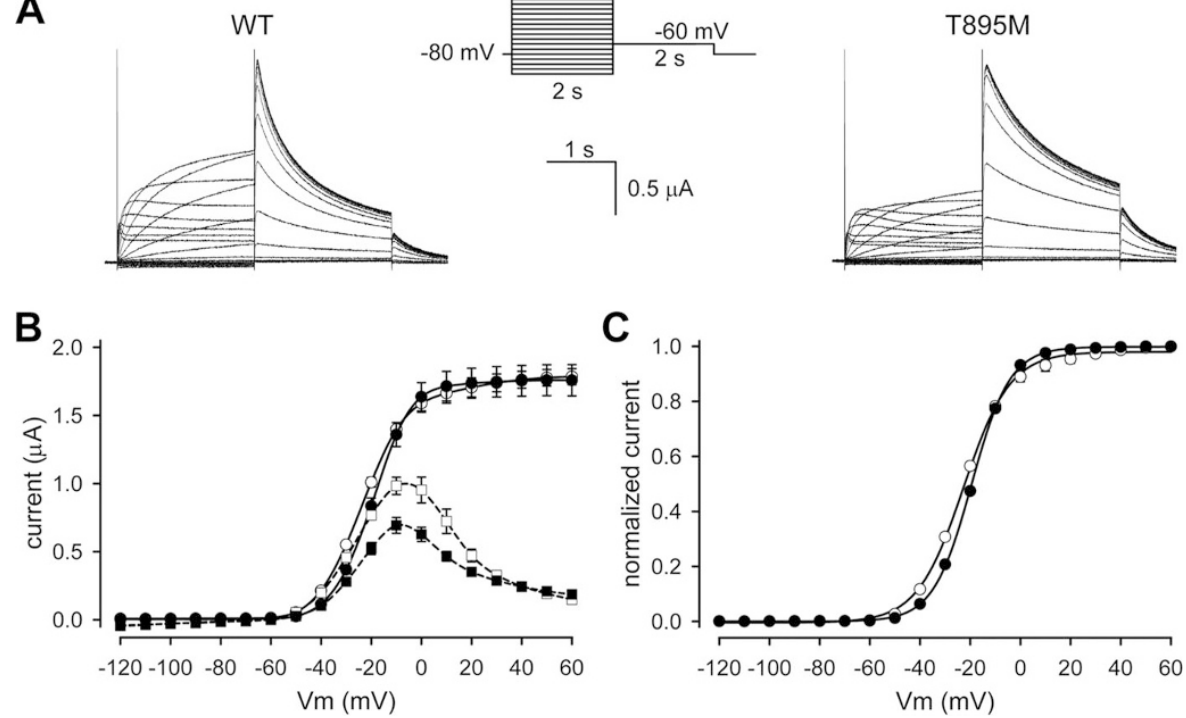

C
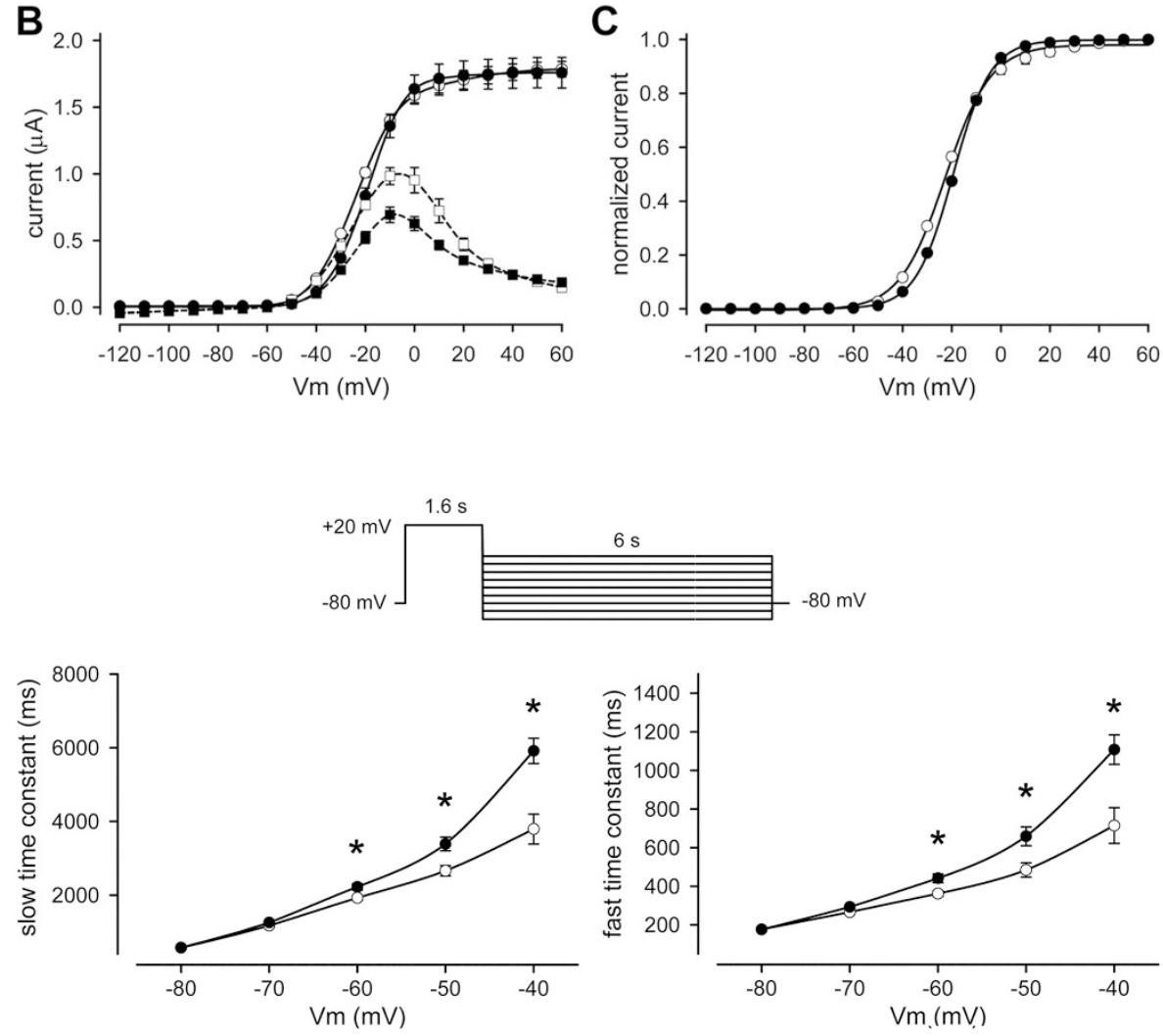

Figure 1. Characteristics of WT and T895M $\mathrm{KCNH} 2$ currents. (A) Representative current traces of WT (left) and T895M (right) elicited by a twostep voltage clamp protocol (inset). Oocytes were clamped at a holding potential of $-80 \mathrm{mV}$, and $2 \mathrm{~s}$ pulses of voltage from -120 to $+60 \mathrm{mV}$ were imposed in steps of $10 \mathrm{mV}$. Tail currents were recorded by stepping to $-60 \mathrm{mV}$ for $2 \mathrm{~s}$. (B) The average amplitudes of steady-state (squares) and peak-tail (circles) currents. (C) Voltage dependence of activation: Activation curves were obtained by plotting the normalized tail currents as a function of the prepulse potential. The voltages for half-maximal activation were obtained by fitting with the Boltzmann equation (solid lines). Some error bars are smaller than symbols. In each panel of $(B)$ and $(C)$, open circles or squares correspond to WT $(n=10)$, and closed circles or squares correspond to T895M $(n=10)$.

Figure 2. Deactivation kinetics of WT and T895M KCNH2 channels: Deactivation time constants were obtained by fitting a biexponential function (slow and fast time constant) of the decaying currents elicited by a $6 \mathrm{~s}$ test pulse between -100 and $-20 \mathrm{mV}$ preceded by a $1.6 \mathrm{~s}$ prepulse to $+20 \mathrm{mV}$ (inset). The curves that failed to fit the biexponential function were not included $\left\{{ }^{*} p<\right.$ 0.001 vs control, (WT: open circles, $n=10$, T895M: closed circles, $n=10)\}$.

$0.2(p<0.05)\}$, whereas that of F1705S showed a large hyperpolarizing shift by $-17 \mathrm{mV}\left\{\mathrm{F} 1705 \mathrm{~S}: V_{0.5}=-105.3 \pm\right.$ $1.2 \mathrm{mV}(p<0.001), \kappa=7.7 \pm 0.2(P=\mathrm{NS})\}$ (Fig. $3 B$, left). The hyperpolarizing shifts of the inactivation curve were showing that the voltage dependence of inactivation was increased in G1084S and F1705S. The $V_{0.5}$ values of activation in G1084S and F1705S were comparable with WT, but the slope factors were significantly different $\left\{\mathrm{WT}: V_{0.5}=\right.$ $-44.4 \pm 0.7 \mathrm{mV}, \kappa=-6.2 \pm 0.2 ; \mathrm{G} 1084 \mathrm{~S}: V_{0.5}=-42.9 \pm$ $1.1 \mathrm{mV}(P=\mathrm{NS}), \kappa=-7.3 \pm 0.2(p<0.05) ; \mathrm{F} 1705 \mathrm{~S}: V_{0.5}=$ $-45.4 \pm 1.0 \mathrm{mV}(p=\mathrm{NS}), \kappa=-8.0 \pm 0.1(p<0.001)\}$, showing small but significant differences in the voltagedependence of activation (Fig. $3 B$, right). The time constants of fast $\left(\tau_{\mathrm{f}}\right)$ or slow $\left(\tau_{\mathrm{s}}\right)$ recovery components were significantly larger in F1705S than WT, whereas G1084S only slightly affected the time constants $\left\{\mathrm{WT}: \tau_{\mathrm{f}}=14.7 \pm 1.8 \mathrm{~ms}\right.$, $\tau_{\mathrm{s}}=120.4 \pm 19.0 \mathrm{~ms} ; \mathrm{G} 1084 \mathrm{~S}: \tau_{\mathrm{f}}=15.2 \pm 1.2 \mathrm{~ms}(P=\mathrm{NS})$, $\tau_{\mathrm{s}}=361.2 \pm 165.3 \mathrm{~ms}(p<0.05)$; F1705S: $\tau_{\mathrm{f}}=29.6 \pm 2.8$ $\left.\mathrm{ms}(p<0.001), \tau_{\mathrm{s}}=455.2 \pm 104.7 \mathrm{~ms}(p<0.001)\right\}$, showing significantly delayed recovery kinetics in F1705S (Fig. 3C).

\section{DISCUSSION}

The present study provides a possible causal association between SIDS and major cardiac channelopathy with a detailed functional assessment. We detected five mutations, KCNQ1-K598R, KCNH2-T895M, SCN5A-F532C, SCN5AG1084S, and SCN5A-F1705S, in four cases.

We did not find significant gating changes in $K C N Q 1$ K598R and we cannot deny the possibility that the KCNQ1$\mathrm{K} 598 \mathrm{R}$ is a rare polymorphism. However, KCNQ1-K598 is an evolutionally conserved amino acid residue and the K598R (c.1793A > G) possibly changes the splicing site based on a computer splice prediction program (SpliceView, http:// bioinfo.itb.cnr.it/oriel/splice-view.html) (data not shown). Our expression experiments using oocytes and the KCNQ1-K598R cRNA may not reflect in vivo gating properties of the channel encoded by KCNQ1-K598R (c.1793A > G).

As for $K C N H 2$, we found the mutation $K C N H 2-T 895 \mathrm{M}$ in one subject who also carried an SCN5A-G1084S mutation. T895 of $K C N H 2$ is located in the C-terminus that extends from residue Y667 to S1159 (34), and little information was 

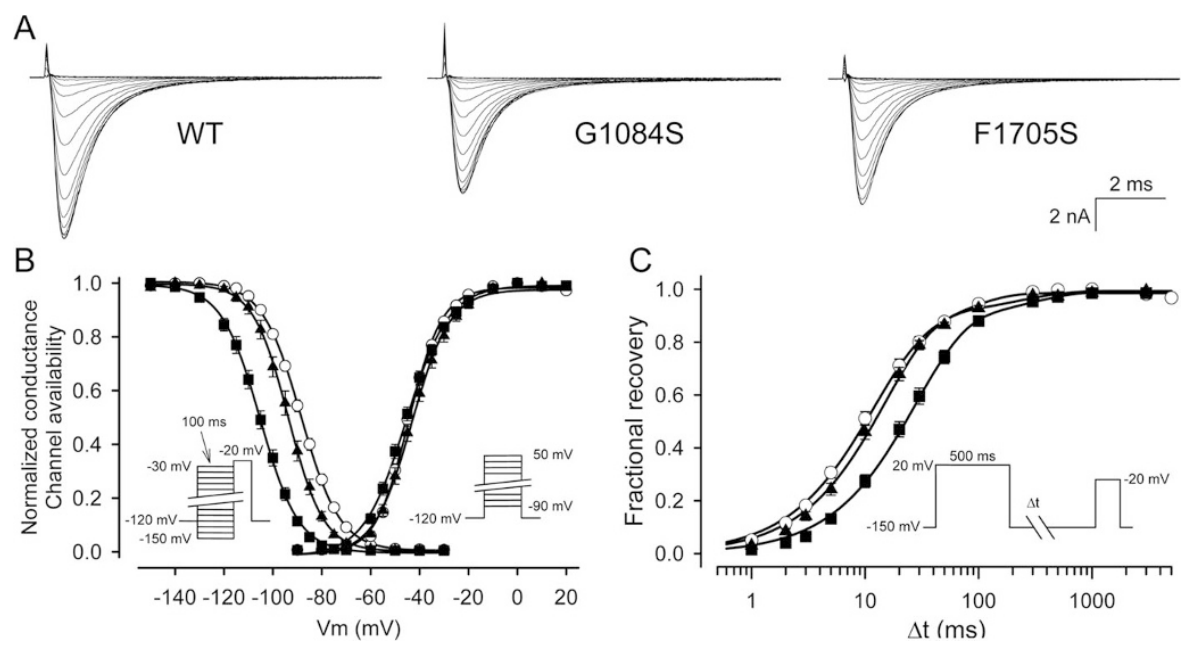

Figure 3. Characteristics of WT, G1084S and F1705S SCN5A currents. (A) Representative whole-cell current traces of WT (left), G1084S (center), and F1705S (right) SCN5A channels expressed in tsA-201 cells. Currents were elicited by a $-20 \mathrm{mV}$ test potential after a series of $100 \mathrm{~ms}$ prepulses from -150 to $-30 \mathrm{mV}$ as shown in $(B)$ inset $(l e f t)$. $(B)$ Conductance-voltage relationship and steady-state availability for inactivation. Currents for measuring conductance were recorded at membrane potentials from -90 to $50 \mathrm{mV}$ from a holding potential of $-120 \mathrm{mV}$ (right inset). The conductance was estimated with the equation $G=I /\left(V_{\mathrm{m}}\right.$ $-E_{\text {rev }}$ ), where $G$ is conductance, $I$ represents the peak test-pulse current, $V_{\mathrm{m}}$ is the test-pulse potential, and $E_{\text {rev }}$ is the measured reversal potential. Normalized peak conductance was plotted as a function of membrane potential. The data from the test potentials higher than $20 \mathrm{mV}$ were omitted. Steady-state availability for inactivation was assessed by the protocol shown in the inset (left). Normalized peak current and conductance were fit with the Boltzmann equation (WT: open circles, $n=37$, G1084S: closed triangles, $n=8$, F1705S: closed squares, $n=10)$. (C) Recovery from inactivation. Recovery from inactivation was measured by a double pulse protocol as shown in the inset. Fractional recovery was determined as the ratio of peak currents measured at $-20 \mathrm{mV}$ after a given test interval $(\Delta \mathrm{t})$ to the maximum peak current (WT: open circles, $n=30$, G1084S: closed triangles, $n=8$, F1705S: closed squares, $n=10$ ).

available about the mechanisms for $K C N H 2$ channel dysfunction caused by the mutations in the C-terminus except for their involvement in trafficking (35). KCNH2-S818L was reported to partly alter channel gating (36) and polymorphic $K C N H 2$ K897T was reported to produce a modest abbreviation of QTc by shifting the voltage of activation of $I_{\mathrm{Kr}}$ (37). Biophysical properties of the $\mathrm{KCNH} 2-\mathrm{T} 895 \mathrm{M}$ potassium channels included a decrease in amplitude of the steady state current and a delay in deactivation. Since these two gating abnormalities seem to result in opposite functional effects, it is difficult to predict the overall influence of the T895M mutation. The subject with KCNH2-T895M also carried SCN5A-G1084S. SCN5A-G1084S is located in the cytoplasmic II-III interdomain linker, where several mutations have been reported in cases associated with LQTS $(38,39)$. A997S, located in the II-III linker, has been reported in one case of SIDS and an electrophysiological study showed a gain-of-function phenotype characterized by persistent and increased inward sodium current (20). SCN5A-G1084S caused a significant hyperpolarizing shift of steady-state inactivation, however, the change was not so remarkable and G1084S is predicted to change a nonconserved amino acid residue, suggesting that SCN5AG1084S may be a rare polymorphism. Although the pathogenetic role of $\mathrm{KCNH} 2-\mathrm{T} 895 \mathrm{M}$ in SIDS remains unclear, one possibility is that a subtle disturbance of the $\mathrm{KCNH} 2$ current due to the balance of opposite gating abnormalities increases arrhythmogenecity under the influence of additional factors such as SCN5A-G1084S. Furthermore, another possibility is that LQTS coexisted with Brugada syndrome in a single patient. One mutation $(\mathrm{KCNH} 2-\mathrm{T} 895 \mathrm{M})$ is responsible for LQT2, the other (SCN5A-G1084S) for Brugada syndrome. Since these two mutations had different gating properties, they might have an equal chance to cause fatal arrhythmias in the patient.
Among five mutations found in this study, three are mutations of SCN5A, namely F532C, G1084S, and F1705S. Mutations of SCN5A account for approximately 5-10\% of cases of LQTS $(38,39)$, and increasing attention has focused on SCN5A mutations as the cause of SIDS because of the high risk of a cardiac event during sleep in individuals carrying these mutations. Schwartz et al. (17) first reported an SCN5A mutation in a SIDS victim and Ackerman et al. (20) detected SCN5A mutations in two of 93 SIDS victims in a postmortem molecular analysis. Among the mutations in LQTS genes, SCN5A mutation may be most frequently associated with SIDS.

The SCN5A-F532C channel did not show any significant difference in properties in the expression experiments. However, this mutation was previously reported in an adult with paroxysmal atrial fibrillation and atrial tachycardia, and not in 232 healthy controls (28), indicating that it is probably associated with SIDS. The heterologously expressed SCN5AF1705S channel exhibited profound gating abnormalities. This mutation was detected in a 27-d-old girl, the youngest of the subjects in which a mutation was found in the present study. The hyperpolarizing shift of steady-state inactivation and delayed recovery from inactivation would reduce the availability of $\mathrm{Na}$ channels and delay the conduction of cardiac impulses. These kinetic properties could result in a decrease of net $\mathrm{Na}$ current and this loss-of-function feature supports a proposed linkage between Brugada syndrome and SIDS $(40,41)$.

This study revealed that $9.5 \%$ of Japanese SIDS victims carried mutations of the cardiac ion channel genes, $K C N Q 1$, $K C N H 2$, and SCN5A. Arnestad et al. (24) recently studied seven genes associated with LQTS in 182 SIDS infants in Norway and reported that $9.5 \%$ of cases carried functionally significant variants in LQTS genes. Considering the significant variation in the incidence of SIDS and in cardiac chan- 
nelopathy among racial and ethnic groups, we assumed that the prevalence of ion channel mutations in Japanese SIDS victims might be different. However, the present result suggests that nearly $10 \%$ of SIDS cases in Japan are associated with LQTS gene mutations, which is similar to the rate in Norway. Even though a relatively small cohort was investigated, this study clearly detected LQTS gene mutations in Japanese SIDS victims. Ethnic disparities in the prevalence of SIDS are probably due to other genetic or socioenvironmental factors. Some investigators have recommended widespread ECG-based screening of infants to prevent SIDS $(42,43)$. However, it requires overcoming several problems including the cost of testing, accuracy of interpretation, managing of false-positive ECGs, and efficacy of treatment for those positive with LQTS (44). Little information is available on whether the mutation carriers exhibit ECG abnormalities such as QT prolongation or Brugada-type changes. As pointed out by Tester et al. (45), many individuals may be falsely diagnosed as LQTS, which may raise socioeconomic and psychosocial problems.

Genetic screening is sensitive and possibly detects many mutations, however, it would be sometimes difficult to identify SIDS-associated mutations. Although victims mainly caused by genetic factors would not decrease in the number by the "back to sleep campaign," some of their deaths would be preventable if the primary lesions are unmasked. Establishing a genetic database of SIDS cases and future development of expedited technology, like DNA-microarray analysis, to screen infants may hopefully prevent the tragedy of SIDS.

Acknowledgment. We thank Prof. Atsunori Shinagawa (Department of Biology, Faculty of Science, Yamagata University), for advice on handling Xenopus laevis and its oocytes.

\section{REFERENCES}

1. Krous HF, Beckwith JB, Byard RW, Rognum TO, Bajanowski T, Corey T, Cutz E, Hanzlick R, Keens TG, Mitchell EA 2004 Sudden infant death syndrome and unclassified sudden infant deaths: a definitional and diagnostic approach. Pediatrics 114:234-238

2. Scott CL, Iyasu S, Rowley D, Atrash HK 1998 Postneonatal mortality surveillanceUnited States, 1980-1994. MMWR CDC Surveill Summ 47:15-30

3. Martin JA, Kochanek KD, Strobino DM, Guyer B, MacDorman MF 2005 Annual summary of vital statistics-2003. Pediatrics 115:619-634

4. Opdal SH, Rognum TO 2004 The sudden infant death syndrome gene: does it exist? Pediatrics 114:e506-e512

5. Schneider PM, Wendler C, Riepert T, Braun L, Schacker U, Horn M, Althoff H, Mattern R, Rittner C 1989 Possible association of sudden infant death with partial complement C4 deficiency revealed by post-mortem DNA typing of HLA class II and III genes. Eur J Pediatr 149:170-174

6. Opdal SH, Vege A, Stave AK, Rognum TO 1999 The complement component C4 in sudden infant death. Eur J Pediatr 158:210-212

7. Opdal SH, Opstad A, Vege A, Rognum TO 2003 IL-10 gene polymorphisms are associated with infectious cause of sudden infant death. Hum Immunol 64:11831189

8. Narita N, Narita M, Takashima S, Nakayama M, Nagai T, Okado N 2001 Serotonin transporter gene variation is a risk factor for sudden infant death syndrome in the Japanese population. Pediatrics 107:690-692

9. Weese-Mayer DE, Berry-Kravis EM, Maher BS, Silvestri JM, Curran ME, Marazita ML 2003 Sudden infant death syndrome: association with a promoter polymorphism of the serotonin transporter gene. Am J Med Genet A 117A:268-274

10. Puffenberger EG, Hu-Lince D, Parod JM, Craig DW, Dobrin SE, Conway AR, Donarum EA, Strauss KA, Dunckley T, Cardenas JF, Melmed KR, Wright CA, Liang W, Stafford P, Flynn CR, Morton DH, Stephan DA 2004 Mapping of sudden infant death with dysgenesis of the testes syndrome (SIDDT) by a SNP genome scan and identification of TSPYL loss of function. Proc Natl Acad Sci USA 101:1168911694

11. Kijima K, Sasaki A, Niki T, Umetsu K, Osawa M, Matoba R, Hayasaka K 2004 Sudden infant death syndrome is not associated with the mutation of PHOX2B gene, a major causative gene of congenital central hypoventilation syndrome. Tohoku J Exp Med 203:65-68

12. Horiuchi H, Sasaki A, Osawa M, Kijima K, Ino Y, Matoba R, Hayasaka K 2005 Sensitive detection of polyalanine expansions in PHOX2B by polymerase chain reaction using bisulfite-converted DNA. J Mol Diagn 7:638-640

13. Priori SG, Barhanin J, Hauer RN, Haverkamp W, Jongsma HJ, Kleber AG, McKenna WJ, Roden DM, Rudy Y, Schwartz K, Schwartz PJ, Towbin JA, Wilde AM 1999 Genetic and molecular basis of cardiac arrhythmias: impact on clinical management parts I and II. Circulation 99:518-528

14. Priori SG, Barhanin J, Hauer RN, Haverkamp W, Jongsma HJ, Kleber AG, McKenna WJ, Roden DM, Rudy Y, Schwartz K, Schwartz PJ, Towbin JA, Wilde AM 1999 Genetic and molecular basis of cardiac arrhythmias: impact on clinical management part III. Circulation 99:674-681

15. Maron BJ, Clark CE, Goldstein RE, Epstein SE 1976 Potential role of QT interval prolongation in sudden infant death syndrome. Circulation 54:423-430

16. Sadeh D, Shannon DC, Abboud S, Saul JP, Akselrod S, Cohen RJ 1987 Altered cardiac repolarization in some victims of sudden infant death syndrome. N Engl J Med 317:1501-1505

17. Schwartz PJ, Priori SG, Dumaine R, Napolitano C, Antzelevitch C, Stramba-Badiale M, Richard TA, Berti MR, Bloise R 2000 A molecular link between the sudden infant death syndrome and the long-QT syndrome. N Engl J Med 343:262-267

18. Schwartz PJ, Priori SG, Bloise R, Napolitano C, Ronchetti E, Piccinini A, Goj C, Breithardt G, Schulze-Bahr E, Wedekind H, Nastoli J 2001 Molecular diagnosis in a child with sudden infant death syndrome. Lancet 358:1342-1343

19. Wedekind H, Smits JP, Schulze-Bahr E, Arnold R, Veldkamp MW, Bajanowski T, Borggrefe M, Brinkmann B, Warnecke I, Funke H, Bhuiyan ZA, Wilde AA, Breithardt G, Haverkamp W 2001 De novo mutation in the SCN5A gene associated with early onset of sudden infant death. Circulation 104:1158-1164

20. Ackerman MJ, Siu BL, Sturner WQ, Tester DJ, Valdivia CR, Makielski JC, Towbin JA 2001 Postmortem molecular analysis of SCN5A defects in sudden infant death syndrome. JAMA 286:2264-2269

21. Schulze-Bahr E, Fenge H, Etzrodt D, Haverkamp W, Monnig G, Wedekind H, Breithardt G, Kehl HG 2004 Long QT syndrome and life threatening arrhythmia in a newborn: molecular diagnosis and treatment response. Heart 90:13-16

22. Brugada R, Hong K, Dumaine R, Cordeiro J, Gaita F, Borggrefe M, Menendez TM, Brugada J, Pollevick GD, Wolpert C, Burashnikov E, Matsuo K, Wu YS, Guerchicoff A, Bianchi F, Giustetto C, Schimpf R, Brugada P, Antzelevitch C 2004 Sudden death associated with short-QT syndrome linked to mutations in HERG. Circulation 109:30-35

23. Christiansen M, Tonder N, Larsen LA, Andersen PS, Simonsen H, Oyen N, Kanters JK, Jacobsen JR, Fosdal I, Wettrell G, Kjeldsen K 2005 Mutations in the HERG $\mathrm{K}+$-ion channel: a novel link between long QT syndrome and sudden infant death syndrome. Am J Cardiol 95:433-434

24. Arnestad M, Crotti L, Rognum TO, Insolia R, Pedrazzini M, Ferrandi C, Vege A, Wang DW, Rhodes TE, George AL Jr., Schwartz PJ 2007 Prevalence of long-QT syndrome gene variants in sudden infant death syndrome. Circulation 115:361-367

25. Lin C, Nagai M, Ishigaki D, Hayasaka K, Endoh M, Ishii K 2005 Cross-talk between beta(1)-adrenoceptors and ET(A) receptors in modulation of the slow component of delayed rectifier $\mathrm{K}(+)$ currents. Naunyn Schmiedebergs Arch Pharmacol 371:133-140

26. Ishii K, Nagai M, Takahashi M, Endoh M 2003 Dissociation of E-4031 from the HERG channel caused by mutations of an amino acid results in greater block at high stimulation frequency. Cardiovasc Res 57:651-659

27. Makita N, Horie M, Nakamura T, Ai T, Sasaki K, Yokoi H, Sakurai M, Sakuma I, Otani H, Sawa H, Kitabatake A 2002 Drug-induced long-QT syndrome associated with a subclinical SCN5A mutation. Circulation 106:1269-1274

28. Maekawa K, Saito Y, Ozawa S, Adachi-Akahane S, Kawamoto M, Komamura K, Shimizu W, Ueno K, Kamakura S, Kamatani N, Kitakaze M, Sawada J 2005 Genetic polymorphisms and haplotypes of the human cardiac sodium channel alpha subunit gene (SCN5A) in Japanese and their association with arrhythmia. Ann Hum Genet 69:413-428

29. Barhanin J, Lesage F, Guillemare E, Fink M, Lazdunski M, Romey G 1996 $\mathrm{K}(\mathrm{V}) \mathrm{LQT} 1$ and $1 \mathrm{KK}(\mathrm{minK})$ proteins associate to form the $\mathrm{I}(\mathrm{Ks})$ cardiac potassium current. Nature 384:78-80

30. Sanguinetti MC, Curran ME, Zou A, Shen J, Spector PS, Atkinson DL, Keating MT 1996 Coassembly of K(V)LQT1 and minK (IsK) proteins to form cardiac I(Ks) potassium channel. Nature 384:80-83

31. Smith PL, Baukrowitz T, Yellen G 1996 The inward rectification mechanism of the HERG cardiac potassium channel. Nature 379:833-836

32. Sanguinetti MC, Jiang C, Curran ME, Keating MT 1995 A mechanistic link between an inherited and an acquired cardiac arrhythmia: HERG encodes the IKr potassium channel. Cell 81:299-307

33. Kiehn J, Lacerda AE, Wible B, Brown AM 1996 Molecular physiology and pharmacology of HERG. Single-channel currents and block by dofetilide. Circulation 94:2572-2579

34. Warmke JW, Ganetzky B 1994 A family of potassium channel genes related to eag in drosophila and mammals. Proc Natl Acad Sci USA 91:3438-3442

35. Sasano T, Ueda K, Orikabe M, Hirano Y, Kawano S, Yasunami M, Isobe M, Kimura A, Hiraoka M 2004 Novel C-terminus frameshift mutation, 1122fs/147, of HERG in LQT2: additional amino acids generated by frameshift cause accelerated inactivation. J Mol Cell Cardiol 37:1205-1211

36. Nakajima T, Kurabayashi M, Ohyama Y, Kaneko Y, Furukawa T, Itoh T, Taniguchi Y, Tanaka T, Nakamura Y, Hiraoka M, Nagai R 2000 Characterization of S818L mutation in HERG C-terminus in LQT2. Modification of activation-deactivation gating properties. FEBS Lett 481:197-203

37. Bezzina CR, Verkerk AO, Busjahn A, Jeron A, Erdmann J, Koopmann TT, Bhuiyan ZA, Wilders R, Mannens MM, Tan HL, Luft FC, Schunkert H, Wilde AA 2003 A 
common polymorphism in KCNH2 (HERG) hastens cardiac repolarization. Cardiovasc Res 59:27-36

38. Tester DJ, Will ML, Haglund CM, Ackerman MJ 2005 Compendium of cardiac channel mutations in 541 consecutive unrelated patients referred for long QT syndrome genetic testing. Heart Rhythm 2:507-517

39. Splawski I, Shen J, Timothy KW, Lehmann MH, Priori S, Robinson JL, Moss AJ, Schwartz PJ, Towbin JA, Vincent GM, Keating MT 2000 Spectrum of mutations in long-QT syndrome genes. KVLQT1, HERG, SCN5A, KCNE1, and KCNE2. Circulation 102:1178-1185

40. Priori SG, Napolitano C, Giordano U, Collisani G, Memmi M 2000 Brugada syndrome and sudden cardiac death in children. Lancet 355:808-809
41. Wan X, Chen S, Sadeghpour A, Wang Q, Kirsch GE 2001 Accelerated inactivation in a mutant $\mathrm{Na}(+)$ channel associated with idiopathic ventricular fibrillation. Am J Physiol Heart Circ Physiol 280:H354-H360

42. Quaglini S, Rognoni C, Spazzolini C, Priori SG, Mannarino S, Schwartz PJ 2006 Cost-effectiveness of neonatal ECG screening for the long QT syndrome. Eur Heart J 27:1824-1832

43. Schwartz PJ 2006 Pro: Newborn ECG screening to prevent sudden cardiac death Heart Rhythm 3:1353-1355

44. van Langen IM, Wilde AA 2006 Con: Newborn screening to prevent sudden cardiac death? Heart Rhythm 3:1356-1359

45. Tester DJ, Ackerman MJ 2005 Sudden infant death syndrome: How significant are the cardiac channelopathies? Cardiovasc Res 67:388-396 